\title{
Low Molecular Weight Iron and the Oxygen Paradox in Isolated Rat Hearts
}

\author{
Arthur Voogd, Wim Sluiter, Henk G. van Eijk, * and Johan F. Koster \\ Departments of Biochemistry and *Chemical Pathology, Medical Faculty, Erasmus University Rotterdam, \\ 3000 DR Rotterdam, The Netherlands
}

\begin{abstract}
Little is known about changes in the amount of iron in the intracellular low molecular weight pool, which catalyzes the Fenton reactions during reperfusion after ischemia. In this study a new approach is presented to measure low molecular weight iron and it is applied to normal hearts during ischemia and to iron-loaded hearts during anoxia and reoxygenation. The results of this study show that $(a)$ during ischemia in normal hearts a progressive 30-fold increase occurs in low molecular weight iron after $45 \mathrm{~min}$ of ischemia, whereas $(b)$ during $45 \mathrm{~min}$ of anoxic perfusion the low molecular weight iron does not increase. This means that the reductive release from the storage protein ferritin is greatly enhanced by the acidification that occurs during ischemia. (c) Anoxic perfusion of iron-loaded hearts does increase low molecular weight iron and there is a further increase upon reoxygenation, which is prevented by $(+)$-cyanidanol-3. Based on these findings it is concluded that oxygen deprivation enhances the susceptibility of rat hearts to oxygen radicals by increasing the amount of catalytic, ferrous iron in the low molecular weight pool. (J. Clin. Invest. 1992.90:2050-2055.) Key words: oxygen free radicals • deferoxamine $\bullet$ ischemia $\bullet$ anoxia $\bullet$ reperfusion
\end{abstract}

\section{Introduction}

The generation of oxygen-centered free radicals is thought to contribute to the exacerbation of tissue injury upon restoration of the oxygen supply to ischemic organs $(1,2)$. This hypothesis is based on protective effects of the addition of scavengers of superoxide, hydrogen peroxide, and the hydroxyl radical (37 ). Direct measurements of the radical adducts of spintrap agents have since confirmed that these radicals are generated $(8,9)$. However, neither superoxide nor hydrogen peroxide are very toxic in themselves, but in the presence of a transition metal, such as iron or copper, the very toxic hydroxyl radical or ferryl ion is formed (10). The significance of iron to ischemia and reperfusion is supported by studies in which iron chelation protects postischemic tissue (11-13). In addition to the circumstantial evidence on the basis of iron chelation, we have shown that the hearts from iron-loaded rats are very sensitive to reoxygenation after a mild anoxic insult (14).

Address correspondence and reprint requests to Dr. A. Voogd, Department of Biochemistry I, Medical Faculty, Erasmus University Rotterdam, P.O. Box 1738, 3000 DR Rotterdam, The Netherlands.

Received for publication 27 January 1992 and in revised form 1 June 1992

J. Clin. Invest.

(C) The American Society for Clinical Investigation, Inc.

$0021-9738 / 92 / 11 / 2050 / 06 \$ 2.00$

Volume 90, November 1992, 2050-2055
Under normal conditions only a minute quantity of the intracellular iron is present in a low molecular weight pool. This iron is bound to weak chelators such as AMP and ATP (15) and in this form iron is able to catalyze hydroxyl radical formation $(16,17)$. The bulk of the intracellular iron exists as $\mathrm{Fe}(\mathrm{OH})_{3}$ stored in ferritin and as heme iron in a variety of proteins. This iron is not available to catalyze hydroxyl radical formation. It has been shown that superoxide can mobilize iron from ferritin and that this iron can catalyze hydroxyl radical formation $(18,19)$. In addition, other reducing agents such as reduced flavins can cause the reductive release of iron from ferritin $(20,21)$. This makes ferritin a potentially hazardous biomolecule under pathological conditions when sufficient reducing equivalents are available. It is therefore important to investigate whether there is a rise in low molecular weight iron during ischemia or anoxia and after reoxygenation to appreciate the contribution to tissue injury under these conditions.

There are reports in which an increase in low molecular weight iron has been found during ischemia. However, both Holt et al. (22) and Komara et al. (23) neglected the possibility that iron was released from ferritin during their procedures to isolate the low molecular weight pool. Healing et al. (24) realized the possibility but argue that since the iron they measure is chelatable, it must have been loosely bound and therefore potentially catalytic.

The purpose of this study is to present an alternative procedure to measure low molecular weight iron that circumvents the drawbacks mentioned above. Using this method, we have investigated the changes in the low molecular weight iron pool during no-flow ischemia, which causes a profound acidosis $(\mathrm{pH}<6)$, and during anoxic perfusion where the cellular $\mathrm{pH}$ remains constant. In addition we have extended this study to hearts from iron-loaded rats. These hearts, which contain twice as much total iron as control hearts, were shown to be very sensitive to anoxia and reoxygenation (14). The iron in these hearts is predominantly located in the endothelium but the dramatic loss of contractility that occurs could not be correlated with morphological indications of injury in endothelial cells (Voogd, A., A. M. M. van der Kraaij, H. G. van Eijk, C. E. Essed, and J. F. Koster, manuscript submitted for publication). To evaluate the role of low molecular weight iron in these hearts we have measured the size of the low molecular weight pool during anoxia and reoxygenation.

\section{Methods}

\section{Animals and perfusion protocol}

12-14-wk-old male Wistar rats were used. After a brief anesthesia with diethyl ether the hearts were excised and placed in ice-cold tyrode buffer. The excised hearts were cannulated through the aorta and perfused retrogradely according to Langendorff (25). The perfusions were carried out at $37^{\circ} \mathrm{C}$ and $\mathrm{pH} 7.4$ using a modified Tyrode's buffer containing the following $(\mathrm{mM}): 128 \mathrm{NaCl}, 4.7 \mathrm{KCl}, 1.3 \mathrm{CaCl}_{2}, 20.2$ $\mathrm{NaHCO}_{3}, 0.4 \mathrm{NaH}_{2} \mathrm{PO}_{4}, 1.0 \mathrm{MgCl}_{2}$, and 11 glucose saturated with 
95\% $\mathrm{O}_{2}$ and $5 \% \mathrm{CO}_{2}$. Perfusion pressure was held constant at 80 cm $\mathrm{H}_{2} \mathrm{O}$.

\section{Iron overloading}

Iron overload in male Wistar rats, 12 wk of age, was achieved by injection of $0.5 \mathrm{ml}$ Imferon (iron-dextran, $50 \mathrm{mg} \mathrm{Fe} / \mathrm{ml}$; Fisons Corporation, Leusden, The Netherlands) in the gluteus muscles, after a brief anesthesia with diethyl ether, once a week for a period of $6 \mathrm{wk}$ and by adding a supplement of iron $\left(\mathrm{FeSO}_{4} \cdot 7 \mathrm{H}_{2} \mathrm{O} ; 7.5 \mathrm{mg} \mathrm{Fe} / \mathrm{g}\right.$ standard food) to their food during this period (14).

\section{Ischemia and anoxia}

Hearts were always perfused with normoxic Tyrode for $\geq 15 \mathrm{~min}$ before either ischemia or anoxia was induced. Warm, no-flow ischemia was induced by stopping coronary flow completely while the heart was submerged in Tyrode buffer saturated with $95 \% \mathrm{~N}_{2}$ and $5 \% \mathrm{CO}_{2}$ and kept at $37^{\circ} \mathrm{C}$. Reperfusion is achieved by restoring coronary flow. Anoxia was caused by perfusing the hearts with tyrode containing glucose (11 mM) saturated with $95 \% \mathrm{~N}_{2}$ and $5 \% \mathrm{CO}_{2}$. Reoxygenation is achieved by changing to the normoxic tyrode.

\section{Low molecular weight iron measurements}

The hexadentate (26) iron chelator deferoxamine forms a 1:1 complex (HDFX-Fe, $K_{\mathrm{as}}=10^{31}$ or $\mathrm{H}_{2} \mathrm{DFX}-\mathrm{Fe}, K_{\mathrm{as}}=10^{21}$, [27]) with iron, which is known as ferrioxamine. Therefore there is a linear relation between the ratio ferrioxamine/deferoxamine and original iron concentration after addition of excess deferoxamine to iron-containing solutions or tissue homogenates. The very high stability of the complex ensures that all iron is extracted from the weaker intracellular chelators. In this study iron was measured as the ratio of ferrioxamine to deferoxamine formed in incubations at $37^{\circ} \mathrm{C}$ of $10,000 \mathrm{~g}$ supernatant of heart homogenates with $2 \mathrm{mM}$ deferoxamine as described by Gower et al. (28). In this procedure all the iron in the low molecular weight pool is chelated within $1 \mathrm{~h}$. However, it also leads to the removal of iron from ferritin, which is linear in time over $\geq 2 \mathrm{~h} \mathrm{(29)}$. To obtain the actual amount of low molecular weight iron we have followed the increase in ferrioxamine in these incubations in time by measuring ferrioxamine/deferoxamine after 5, 30, 60, 90, and $120 \mathrm{~min}$. Next, we have subtracted the linear increase between 60 and $120 \mathrm{~min}$ from the 60-min value.

\section{Tissue preparation and ferrioxamine/deferoxamine determination}

Immediately after the experiment rat hearts were blotted dry, weighed, and homogenized to a $20 \% \mathrm{wt} / \mathrm{vol}$ homogenate in $100 \mathrm{mM}$ Tris $/ \mathrm{HCl}$, $\mathrm{pH}$ 7.4. Homogenate was centrifuged at $10,000 \mathrm{~g}$ for $15 \mathrm{~min}$ and $1-\mathrm{ml}$ samples were taken from the supernatant, was brought to $2 \mathrm{mM}$ deferoxamine by adding $100 \mu \mathrm{l}$ of $22 \mathrm{mM}$ deferoxamine, and was incubated at $37^{\circ} \mathrm{C}$. Incubations were stopped by passing the sample through a cartridge (Sep Pak C18; Millipore Corp., Milford, MA) preeluted with $5 \mathrm{ml}$ methanol followed by $5 \mathrm{ml}$ distilled water, on which ferrioxamine and deferoxamine are retained. After application of the sample the cartridge was washed with $5 \mathrm{ml}$ distilled water and deferoxamine and ferrioxamine were eluted with $2 \mathrm{ml}$ methanol and the eluate was applied to the HPLC column.

\section{HPLC analysis}

HPLC was performed with dual LKB 2150 pumps (LKB Instruments, Inc., Gaithersburg, MD), controlled through the LKB 2152 LC controller equipped with automatic sample injector. Effluent from the column was passed through two LKB 2151 variable wavelength detectors to allow simultaneous detection of ferrioxamine at $430 \mathrm{~nm}$ and deferoxamine at $229 \mathrm{~nm}$. Pump heads and high pressure tubing are all made of titanium. The stationary phase is a $250 \times 4 \mathrm{~mm}$ i.d. stainless steel cartridge (model RP18; E. Merck, Darmstadt, Germany). The mobile phase consisted of $88 \% 20 \mathrm{mM} \mathrm{Na} 2 \mathrm{HPO} 4 / \mathrm{NaH}_{2} \mathrm{PO}_{4}, 2 \mathrm{mM} \mathrm{Na}$

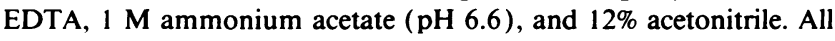

reagents were of HPLC grade and buffers were filtered and degassed before use. Recovery of deferoxamine and ferrioxamine peaks was measured using standard dilutions in methanol and always exceeded $75 \%$. The relation between the ferrioxamine/deferoxamine ratio and the amount of iron was calculated from standards incubated and extracted as the samples.

\section{Experimental design}

Ischemia and reperfusion. The effect of ischemia on low molecular weight iron was determined in hearts that were subjected to warm ischemia for 15, 30, and $45 \mathrm{~min}$. Control hearts were perfused with normoxic buffer for $60 \mathrm{~min}$. To investigate the effect of reperfusion on the low molecular weight iron pool, hearts were subjected to $30 \mathrm{~min}$ of ischemia and low molecular weight iron was determined after $20 \mathrm{~min}$ of reperfusion. The influence of superoxide or iron chelation on low molecular weight iron during reperfusion was determined in two groups of hearts subjected to $30 \mathrm{~min}$ of ischemia and $20 \mathrm{~min}$ of reperfusion in the presence of $30 \mathrm{mg} /$ liter SOD or $50 \mu \mathrm{M}$ deferoxamine.

Anoxia and reoxygenation in iron-loaded rat hearts. To evaluate the effect of anoxia and reoxygenation on the size of the low molecular weight iron pool in iron-loaded hearts, low molecular weight iron was analyzed in normoxic hearts $(n=3)$ and hearts that were perfused with anoxic buffer for $45 \min (n=3)$ and were not reoxygenated or were reoxygenated for $10 \min (n=3)$. To evaluate the effect of iron chelation and antioxidant intervention under those conditions, these experiments were performed with tyrode only or with tyrode containing 50 $\mu \mathrm{M}$ deferoxamine or $20 \mu \mathrm{M}(+)$-cyanidanol-3, which has been shown to scavenge both superoxide and the hydroxyl radical (30).

\section{Statistical evaluation}

All low molecular weight measurements are expressed as $\mathrm{nmol} / \mathrm{g}$ wet weight and presented as mean \pm SEM. Intergroup differences were evaluated by one-way analysis of variance with the Bonferroni option using STATA release 2 (Computing Resource Center, Los Angeles, CA).

\section{Chemicals}

Deferoxamine methanesulfonate (Desferrioxamine mesylate, Desferral) was purchased from Ciba-Geigy (Basel, Switzerland) and (+)cyanidanol-3 was purchased from Zyma (Nyon, Switzerland). (+)cyanidanol-3 buffer was protected from light by wrapping the perfusion apparatus in aluminium foil. Bovine erythrocyte $\mathrm{Cu}-\mathrm{Zn} \operatorname{SOD}(3,000$ $\mathrm{U} / \mathrm{mg}$ ) was purchased from Sigma Chemical Co. (St. Louis, MO).

\section{Results}

Low molecular weight iron determinations. The standard curve (Fig. 1 ) relating the quantity of iron to the ferrioxamine/deferoxamine ratio follows a linear relation with $R^{2}=0.970(P$ $<0.001$ ). Contaminating iron from the chemicals used, determined by extrapolation of this curve to ferrioxamine/deferoxamine $=0$, was consistently low at $2.1 \pm 0.2 \mathrm{nmol} / \mathrm{ml}(n=3$ separate curves). Both slope and background were similar to those presented by Gower et al. (28). To measure the low molecular weight iron pool the $10,000 \mathrm{~g}$ supernatant was incubated with deferoxamine, aliquots are drawn at different time points, and the ferrioxamine/deferoxamine ratio was determined. Initially a rapid rise was found that turns into a linear increase after $1 \mathrm{~h}$ (Fig. 2). The initial rate of iron chelation was lower in the normoxic hearts than in hearts that had been ischemic for $45 \mathrm{~min}$. After $1 \mathrm{~h}$ both curves leveled off to a constant rate of ferrioxamine formation. To evaluate the slope of both curves, regression analysis was performed for the time points $60,90$, and 120 min using time and ischemia ( 0 or 1$)$ as independent variables. This showed that the data can be described by the linear increases as indicated in Fig. 2. Inclusion of the interaction term (time $\times$ ischemia) in the regression analysis 


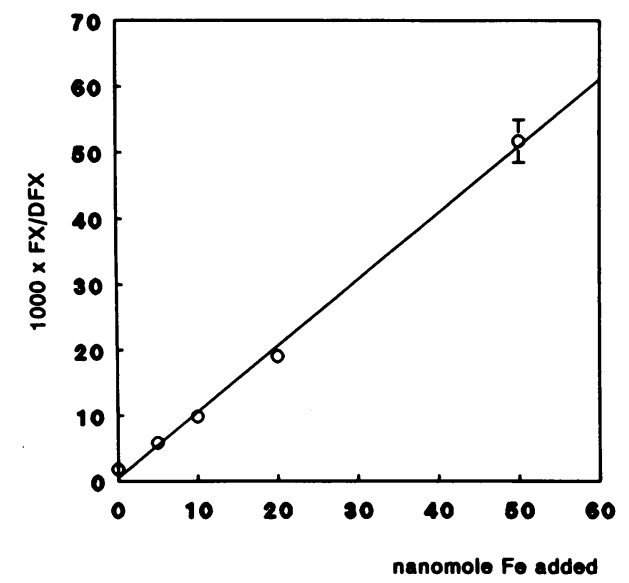

Figure 1. Standard curve. Relationship between the added amount of iron and ferrioxamine/deferoxamine ratio of standard samples extracted and incubated as the experimental samples. Mean \pm SEM of triplicate determinations of one set of samples. Linear regression of these data shows $R^{2}=0.970, P<0.001$. Background iron is calculated by extrapolation to ferrioxamine $/$ deferoxamine $=0$.

showed a nonsignificant contribution, indicating that there is no significant difference in the slope of these curves. No attempt was made to perform nonlinear regression on the earlier data points. This result fits the observations that all the iron in the low molecular weight pool is chelated within $1 \mathrm{~h}(28)$ and that the release of iron from ferritin is linear over $\geq 2 \mathrm{~h} \mathrm{(29).}$ Therefore, to obtain the actual low molecular weight iron in individual hearts, we correct for this ferritin-derived iron by subtracting the amount of iron released between 1 and $2 \mathrm{~h}$ from the amount measured at $1 \mathrm{~h}$.

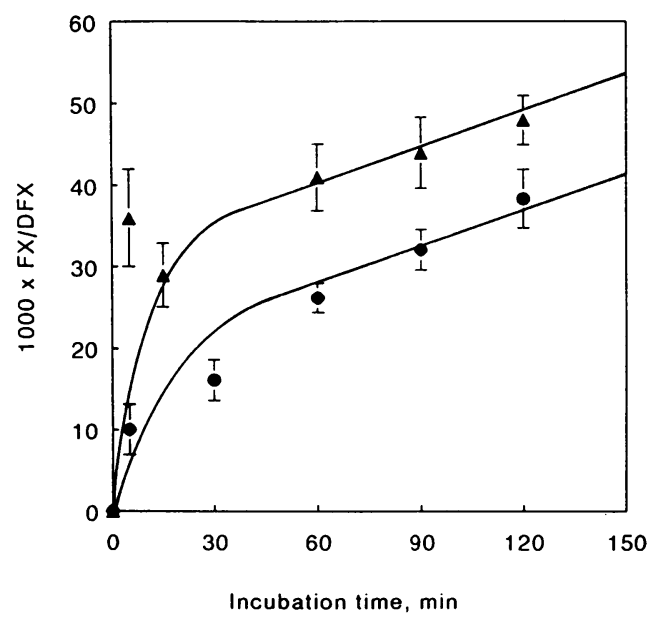

Figure 2. Ferrioxamine formation during incubation of supernatants. Effect of the duration of incubation on the ferrioxamine/deferoxamine ratio of $1 \mathrm{ml}$ supernatant of normoxic rat hearts (circles) or rat hearts subjected to $45 \mathrm{~min}$ ischemia (triangles) with $2 \mathrm{mM}$ deferoxamine. Aliquots of $1 \mathrm{ml}$ from supernatants of individual hearts $(n=3)$ were incubated during the times indicated and processed as described under Methods. Regression analysis using time and ischemia ( 0 or 1$)$ as independent variables results in the equation: ratio $=0.147 \times$ time $+12.0 \times$ ischemia $+19.4\left(R^{2}=0.624\right)$. Inclusion of the interaction term time $\times$ ischemia showed a nonsignificant contribution, indicating that there is no significant difference in the slope of both curves. Each point represents the mean \pm SEM.

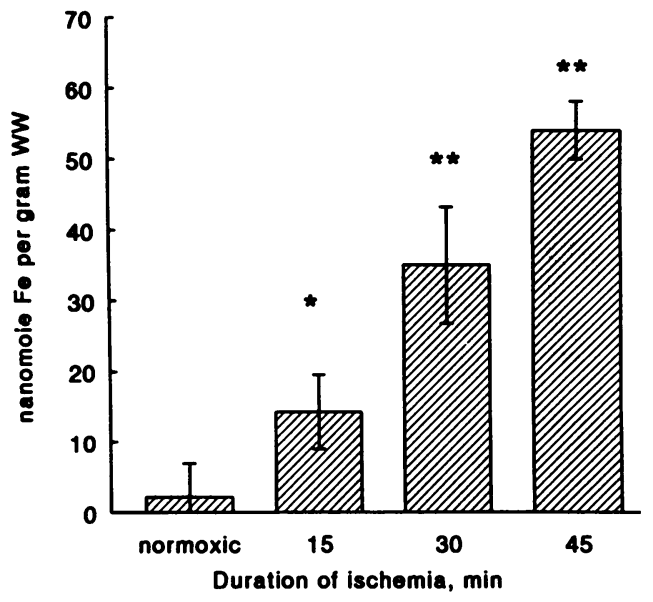

Figure 3. Low molecular weight iron and ischemia. Effect of the duration of warm no-flow ischemia on low molecular weight iron content of rat hearts. Normoxic hearts were perfused with normoxic tyrode for $60 \mathrm{~min}$. Ferrioxamine/deferoxamine ratio was determined in supernatants after 60,90 , and $120 \mathrm{~min}$ and low molecular weight calculated as described under Methods. Each bar represents mean \pm SEM, $n=6 .{ }^{*} P=0.09{ }^{* *} P<0.01$ vs. normoxic controls. Linear regression shows a significant increase in time $P<0.001, R^{2}$ $=0.660$.

The effect of ischemia and reperfusion. To evaluate the effect of ischemia on the low molecular weight iron pool, rat hearts were subjected to warm ischemia for 15, 30, and $45 \mathrm{~min}$. The results (Fig. 3 ) show a progressive increase in low molecular weight iron due to ischemia from $2.1 \pm 4.8 \mathrm{nmol} / \mathrm{g}$ wet weight in normoxic hearts to $54.2 \pm 4.1 \mathrm{nmol} / \mathrm{gram}$ wet weight after $45 \mathrm{~min}$ of ischemia $\left(R^{2}=0.660, P<0.001\right)$.

To investigate the effect of reperfusion in the presence or absence of SOD or deferoxamine on the size of the low molecular weight iron pool, hearts were subjected to $30 \mathrm{~min}$ of ischemia followed by $20 \mathrm{~min}$ of reperfusion. Addition of SOD does not affect low molecular weight iron during reperfusion, whereas iron chelation results in a tremendous decrease in low molecular weight iron (Fig. 4). Both the SOD group and the

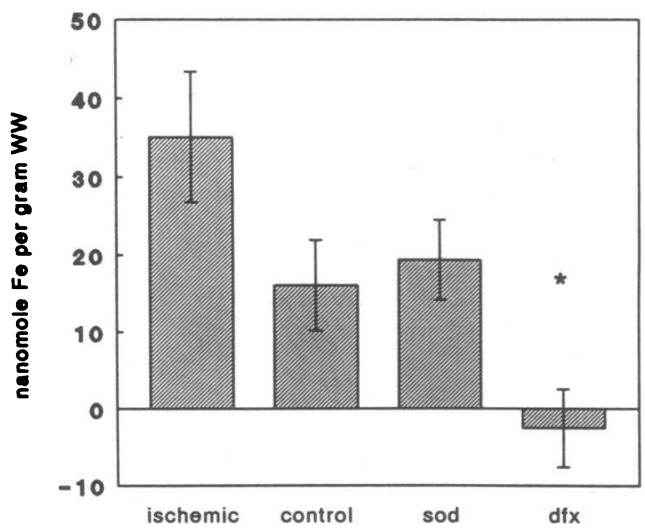

Figure 4. Low molecular weight iron and reperfusion. Effect of 30 min of ischemia (ischemic) and 20 min of reperfusion after $30 \mathrm{~min}$ of ischemia on low molecular weight iron in hearts perfused in the absence (control) or in the presence of SOD (sod) or deferoxamine $(d f x)$. Bars represent mean \pm SEM, $n=6$ for ischemic; $n=3$ for control, sod, and dfx. ${ }^{*} P<0.05$ compared with ischemic hearts. 
control group were lower than the ischemic group but the difference does not reach significance levels. The chelation of the iron into ferrioxamine probably facilitates the washout from the cells.

The effect of anoxia. Anoxia differs substantially from noflow ischemia in that, although there is oxygen depletion, the coronary bed is still perfused. This means that there still is a supply of glucose and removal of metabolites and acidosis is prevented. This makes the latter a mild insult (14). To evaluate the effect of anoxia, the size of the low molecular weight iron pool was compared in hearts that were perfused for $45 \mathrm{~min}$ under normoxic or anoxic conditions. Anoxic perfusion for 45 min does not lead to an increase in the low molecular weight iron content. (Fig. 5, left).

Earlier observations from our laboratory have shown that normal rat hearts, perfused with anoxic buffer for $45 \mathrm{~min}$, regain $80 \%$ of preanoxic contractility upon reoxygenation (14) whereas normal hearts subjected to $15 \mathrm{~min}$ of ischemia regain only $40 \%$ of preischemic contractility (12) upon reperfusion. From the results described above it is clear that ischemia leads to a tremendous increase in low molecular weight iron and to severe damage, whereas anoxia leads to little or no increase in low molecular weight iron and the consequences are mild. Iron-loaded hearts, however, regain only $20 \%$ of pre-anoxic contractility after $45 \mathrm{~min}$ of anoxic perfusion (14). Therefore we measured the amount of low molecular weight iron in ironloaded hearts. Normoxic iron-loaded hearts have a higher low molecular weight iron pool than normal hearts (Fig. 5). In contrast to normal hearts, the size of this low molecular weight pool increases dramatically during anoxia.

Effect of iron chelation and antioxidant protection in ironloaded hearts. The dramatic loss of function of iron-loaded hearts during anoxia and reoxygenation could be prevented by perfusion with either $(+)$-cyanidanol or deferoxamine (14). Therefore, the size of the low molecular weight iron pool during anoxia and reoxygenation of iron-loaded rat hearts was evaluated under these conditions in a separate experiment.
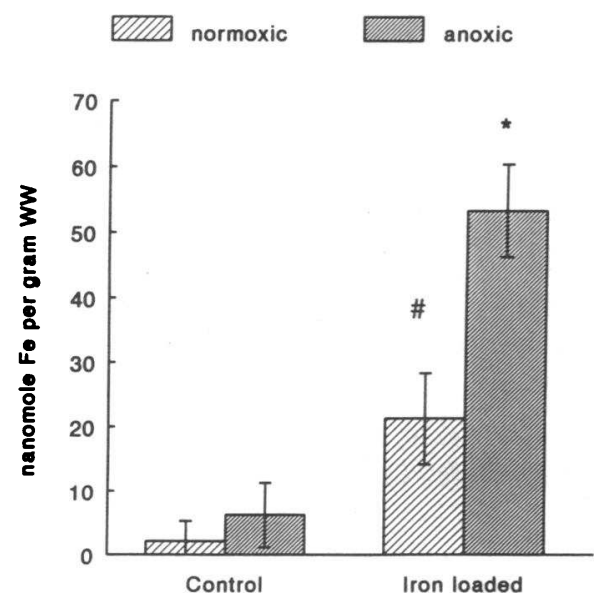

Figure 5. Low molecular weight iron and anoxia. Effect of $45 \mathrm{~min}$ of anoxic perfusion on low molecular weight iron of normal (Control) and iron-loaded rat hearts compared with hearts that were perfused with normoxic tyrode for $60 \mathrm{~min}$. Each bar represents the mean \pm SEM. ( $n=6$ in noniron-loaded hearts and $n=3$ in the ironloaded hearts. ${ }^{*} P<0.05$ vs. normoxic value. ${ }^{*} P<0.05$ vs. noniron loaded).

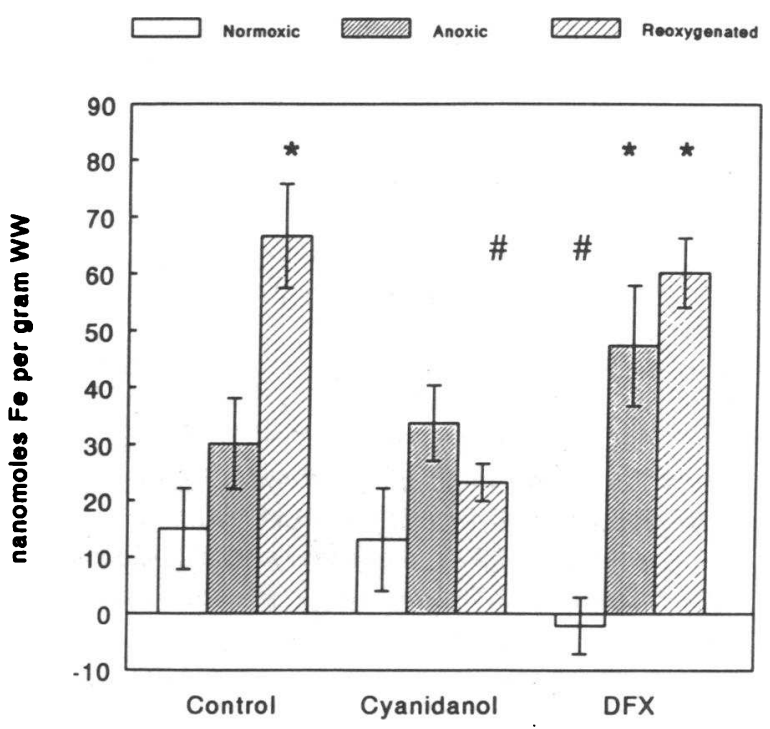

Figure 6. Low molecular weight iron during anoxia and reoxygenation in iron-loaded rat hearts. Effect of $60 \mathrm{~min}$ normoxic perfusion (Normoxic), 45 min anoxic perfusion (Anoxic), and reoxygenation after $45 \mathrm{~min}$ anoxia for $10 \mathrm{~min}$ (Reoxygenation) in the absence (Control) or presence of $20 \mu \mathrm{M}(+)$-cyanidanol (Cyanidanol) or 50 $\mu \mathrm{M}$ deferoxamine $(D F X)$. Each bar represents the mean $\pm \operatorname{SEM}(n$ $=3) .{ }^{*} P<0.05$ vs. normoxic hearts in that group. ${ }^{*} P<0.05$ vs. untreated control.

The size of the low molecular weight iron pool in normoxic iron-loaded rat hearts amounted to $15.4 \pm 6.1 \mathrm{nmol} / \mathrm{g}$ wet weight (Fig. 6, Control). Perfusion with anoxic buffer led to the expected increase of low molecular weight iron. Upon reoxygenation a further increase was found. The low molecular weight pool in iron-loaded hearts is unaffected by normoxic perfusion with $20 \mu \mathrm{M}(+)$-cyanidanol-3 for $1 \mathrm{~h}$ and during anoxic perfusion the same increase was found as in control hearts (Fig. 6, Cyanidanol). However, upon reoxygenation no further increase was found. Normoxic perfusion with $50 \mu \mathrm{M}$ deferoxamine for $1 \mathrm{~h}$ led to a very small low molecular weight iron pool (Fig. 6, $D F X$ ). This could be due to washout from ferioxamine from the heart. Anoxic perfusion in the presence of deferoxamine again increased low molecular weight iron, and upon reoxygenation there is a further increase of low molecular weight iron.

\section{Discussion}

In the present paper we have presented a method to determine the size of the intracellular low molecular weight iron pool and applied this method to ischemic or anoxic rat hearts. The chelated iron in normoxic rat hearts as measured in 60-min incubations by Gower et al. (28) was $15.44 \pm 6.37 \mathrm{nmol} / \mathrm{g}$ wet weight. In our hands the 60 -min incubations yielded $21.6 \pm 3.6$ $(n=6) \mathrm{nmol}$ chelated iron/g wet weight. After our correction for ferritin-derived iron, the low molecular weight pool contains $2.1 \pm 4.8 \mathrm{nmol} / \mathrm{g}$ wet weight. This figure means that the low molecular weight pool in normoxic rat hearts is so small that it escapes more exact measurement. However, in hearts that had been ischemic, the biphasic time curve of iron chelation from the supernatant shows a faster initial phase whereas there is no significant difference between normoxic and isch- 
emic hearts in the slope after $1 \mathrm{~h}$. Thus correction for this ferritin-derived iron leads to a higher value for the low molecular weight pool.

Our results show that the amount of low molecular weight iron increases dramatically during ischemia from $2.1 \pm 4.8$ to $54.2 \pm 4.1 \mathrm{nmol} / \mathrm{g}$ wet weight. Healing et al. (24) have studied the amount of iron in rabbit kidney homogenates after cold ischemia by measuring ferrioxamine/deferoxamine ratios in homogenates in 60 -min incubations. It was shown that the amount of iron increases from $\sim 15 \mathrm{nmol}$ in nonischemic control to $60 \mathrm{nmol} / \mathrm{g}$ tissue after $72 \mathrm{~h}$ of cold ischemia. However, these authors did not correct for the iron released from ferritin that occurred during this incubation. Others (22) showed that the low molecular weight iron in ischemic and nonischemic myocardium after a $2-\mathrm{h}$ in vivo coronary artery occlusion in dogs increased from 130.6 to $183.2 \mathrm{nmol} / \mathrm{g}$ tissue. In dog brain an increase in low molecular weight iron from 90.5 to 370.4 $\mathrm{nmol} / \mathrm{g}$ wet wt was found after cerebral ischemia induced by cardiac arrest (23). No measurements of total iron were presented in those studies, but mammalian tissue, except liver and spleen, contains $\sim 1,000 \mathrm{nmol} \mathrm{Fe} / \mathrm{g}$ wet weight $(20,31)$. Recalculation of the above results would imply that in mongrel dog brain and heart $10 \%$ of the total iron is in the low molecular weight iron pool under normoxic conditions. This is very high with regard to other estimates in which the low molecular weight iron pools amounts to only $0.2 \%(28)$ or $3 \%(32)$ of the total iron. Possibly these high values can be explained by the fact that during ultrafiltration the homogenate was not buffered and contained only EDTA, which may have led to acidification. Since the iron release from ferritin depends on reducing equivalents and is enhanced by acidification $(20,21)$, additional iron release may have occurred during those incubations.

We have shown that ischemia causes a progressive increase in low molecular weight iron whereas during anoxia low molecular weight iron does not increase in noniron-loaded hearts. To release iron from ferritin a reduction to $\mathrm{Fe}(\mathrm{II})$ must take place and the ferrous iron must be chelated $(20,21)$. One possible mechanism is a superoxide-dependent reduction. However, the iron released through this mechanism has been shown not to exceed $1.5 \mathrm{~mol} \mathrm{Fe} / \mathrm{mol}$ ferritin (33). Furthermore, it is unlikely that superoxide is produced during ischemia and we found no significant difference in the amount of low molecular weight iron in hearts subjected to ischemia and reperfusion with or without SOD. Funk et al. (20) studied the reductive mobilization of iron from isolated horse spleen ferritin. Here it was shown that reduced flavin mononucleotide induces the release of 1,200 Fe atoms / ferritin molecule within $3 \mathrm{~min}$ at $\mathrm{pH}$ 7. At pH 5.1 this was increased to 1,900 atoms Fe. Ischemia causes a drop in intracellular $\mathrm{pH}$ to 5.9 (34) and even to 5.7 after $25 \mathrm{~min}$ (35). Thus, the reducing equivalents present in ischemic tissue and the acidification will facilitate the reductive release of iron from ferritin. During anoxic perfusion coronary flow is maintained, allowing the supply of glucose and the efflux of metabolites. The metabolic consequence is that acidosis is prevented. Therefore, reducing equivalents will be present during anoxia but no acidification occurs. It has to be concluded that the acidification contributes tremendously to the mobilization of iron from ferritin.

The increment of low molecular weight iron during reoxygenation of iron-loaded hearts must have a mechanism other than the increase due to reducing agents during anoxia. This is substantiated by our finding that low molecular weight iron in iron-loaded hearts increased during anoxic perfusion in the presence of $(+)$-cyanidanol-3, whereas the additional increase during reoxygenation was prevented by $(+)$-cyanidanol (Fig. 6, Cyanidanol). This implies that the increase of low molecular weight iron in iron-loaded hearts during reoxygenation is due to superoxide.

Normoxic iron-loaded hearts perfused with deferoxamine for $1 \mathrm{~h}$ show a very small low molecular weight pool. This is probably due to a loss of ferrioxamine to the perfusate, which will deplete the low molecular weight pool first. An increase occurs during anoxia because apparently the reductive release of iron exceeds the washout effect. $10 \mathrm{~min}$ after reoxygenation low molecular weight iron in these hearts was higher than in the (+)-cyanidanol-3 hearts. Again, this could be caused by superoxide production since this is not prevented by deferoxamine.

Normoxic iron-loaded rat hearts have a higher low molecular weight iron content compared with the noniron-loaded hearts. This is without apparent effect on the physiological parameters such as coronary flow or contractility (14). Due to the presence of oxygen, the iron in the low molecular weight iron pool in normoxic iron-loaded hearts is in the ferric state, in which it will not catalyze the formation of hydroxyl radicals directly. In contrast, the low molecular weight iron in anoxic or ischemic hearts must be ferrous iron. Moreover, we have shown here that the amount of low molecular weight ferrous iron is increased by ischemia or anoxia. This will directly form hydroxyl radicals together with the hydrogen peroxide that arises from the dismutation of superoxide that is generated upon reoxygenation. Indeed, the effect of reoxygenation after the anoxic insult is quite dramatic in the iron-loaded hearts and this could be prevented by perfusion with $(+)$-cyaidanol-3 (14). Despite the increase in low molecular weight iron, the iron-loaded hearts perfused with deferoxamine recover up to $80 \%$ of preanoxic contractility (14), which shows that the low molecular weight iron in these hearts is not in a form that catalyzes the Fenton reaction because it is chelated as ferrioxamine (17).

Taken together our results show that the low molecular weight iron pool increases during oxygen deprivation and that this release is due to the reducing equivalents generated in the absence of oxygen. The drop in $\mathrm{pH}$ that occurs in ischemic hearts dramatically increases this reductive iron release. Furthermore, free radicals generated during reoxygenation release additional iron. From these results it can be concluded that ischemia increases the susceptibility to the oxygen radicals generated during reoxygenation by increasing the amount of catalytic, ferrous iron in the low molecular weight pool.

\section{Acknowledgments}

This research was supported solely by the Erasmus University Rotterdam, The Netherlands.

\section{References}

1. McCord, J. M. 1985. Oxygen-derived free radicals in post-ischemic tissue injury. N. Engl. J. Med 312:159-163.

2. Weiss, S. J. 1986. Oxygen, ischemia and inflammation. Acta Physiol. Scand. Suppl. 548:9-37.

3. Bolli, R. 1991. Oxygen derived free radicals and myocardial reperfusion injury: an overview. Cardiovasc. Drugs Ther. 5:249-268.

4. Opie, L. H. 1988. Reperfusion injury and its pharmacologic modification. Circulation. 80:1049-1062.

5. Myers, C. L., S. J. Weiss, M. M. Kirsh, B. M. Shepard, and M. Shlafer. 1986. 
Effects of supplementing hypothermic crystaloid cardioplegic solution with catalase, superoxide dismutase, allopurinol or deferoxamine on functional recovery of globally ischemic and reperfused isolated hearts. J. Thorac. Cardiovasc. Surg. 91:281-289.

6. van der Heide, R. S., P. A. Sobotka, and P. E. Ganote. 1987. Effects of the free radical scavenger DMTU and mannitol on the oxygen paradox in perfused 'rat hearts. J. Mol. Cell. Cardiol. 19:615-625.

7. Hearse, D. J., and A. Tosaki. 1987. Free radicals and reperfusion-induced arrhythmias: protection by spin trap agent $\mathrm{PBN}$ in the rat heart. Circ. Res. 60:375-383.

8. Zweier, J. L. 1988. Measurement of superoxide free radicals in the reperfused heart. J. Biol. Chem. 263:1353-1357.

9. Tosaki, A., I. E. Blasig, T. Pali, and B. Ebert. 1990. Hearts protection and radical trapping by DMPO during reperfusion in isolated working rat hearts. Free Radical Biol. Med. 8:363-372.

10. Halliwell, B., and J. M. C. Gutteridge. 1990. Role of free radicals and catalytic metal ions in human disease: an overview. Methods Enzymol. 186:1-85.

11. Farber, N. E., G. M. Vercellotti, H. S. Jacob, G. M. Pieper, and G. J. Gross. 1988. Evidence for a role of iron-catalyzed oxidants in functional and metabolic stunning in the canine heart. Circ. Res. 63:351-360.

12. van der Kraaij, A. A. M., H. G. van Eijk, and J. F. Koster. 1989. Prevention of post-ischemic cardiac injury by the orally active iron-chelator 1,2-dimethyl-3-hydroxy-4-pyridone (L1) and the antioxidant (+)-cyanidanol-3. Circulation. 80:158-164.

13. Reddy, B. R., R. A. Kloner, and K. Przyklenk. 1989. Early treatment with deferoxamine limits myocardial infarct size. Free Radical Med. Biol. 7:45-72.

14. van der Kraaij, A. M. M., L. J. Mostert, H. G. van Eijk, and J. F. Koster. 1988. Iron-load increases the susceptibility of rat hearts to oxygen reperfusion damage. Protection by the antioxidant $(+)$-cyanidanol-3 and deferoxamine. Circulation. 78:442-449.

15. Weaver, J., and S. Pollack. 1989. Low Mr iron isolated from guinea-pig reticulocytes as AMP-Fe and ATP-Fe complexes. Biochem. J. 265:415-419.

16. Floyd, R. A., and C. A. Lewis. 1983. Hydroxyl free radical generation from hydrogen peroxide by ferrous iron nucleotide complexes. Biochemistry. 22:2645-2649.

17. Graf, E., J. R. Mahoney, R. G. Byrant, and J. W. Eaton. 1984. Iron catalyzed hydroxyl radical formation: stringent requirement for free iron coordination site. J. Biol. Chem. 259:3620-3624.

18. Biemond, P., H. G. van Eijk, A. J. G. Swaak, and J. F. Koster. 1984. Iron mobilization from ferritin by superoxide derived from stimulated polymorphonuclear leukocytes. J. Clin. Invest. 73:1576-1579.

19. Koster, J. F., and R. G. Slee. 1986. Ferritin: a physiological iron donor for microsomal lipid peroxidation. FEBS (Fed. Eur. Biochem. Soc.) Lett. 199:85-88.

20. Funk, F., J.-P. Lenders, R. R. Crichton, and W. Schneider. 1985. Reductive mobilisation of ferritin iron. Eur. J. Biochem. 152:167-172.
21. Sirivech, S., E. Frieden, and S. Osaki. 1974. The release of iron from horse spleen ferritin by reduced flavins. Biochem. J. 143:311-315.

22. Holt, S., M. Gunderson, K. Joyce, N. R. Nayini, G. F. Eyster, A. M Garritano, C. Zonia, G. S. Krause, S. D. Aust, and B. C. White. 1986. Myocardial tissue iron delocalization and evidence of lipid peroxidation after two hours of ischemia. Ann. Emerg. Med. 15:1155-1159.

23. Komara, J. S., N. R. Nayini, H. A. Bialick, R. J. Indrieri, A. M. Garritano, T. J. Hoehner, W. A. Jacobs, R. R. Huang, G. S. Krause, B. C. White, et al. 1986. Brain iron delocalization and lipid peroxidation following cardiac arrest. Ann. Emerg. Med. 15:384-389.

24. Healing, G., J. Gower, B. Fuller, and C. Green. 1990. Intracellular iron redistribution. An important determinant of reperfusion damage to rabbit kidneys. Biochem. Pharmacol. 39:1239-1245.

25. Langendorff, O. 1895. Untersuchungen am überlebenden Säugetierherzen. Pfluegers Arch. Eur. J. Physiol. 61:225-241.

26. Hossein, B. M., M. A. F. Jalal, and D. van der Helm. 1986. The structure of ferrioxamine D1-ethanol-water (1/2/1). Acta Crystallogr. Sect. C Crystal Struct. Commun. C42:1305-1310.

27. Schwarzenbach, G., and K. Schwarzenbach. 1963. Hydroxamatkomplexe I. Die stabilität der eisen(III)-komplexe einfacher hydroxamsäuren und des ferrioxamins B. Helv. Chim. Acta. 46:1390-1400.

28. Gower, J. D., G. Healing, and C. D. Green. 1989. Determination of desferrioxamine available iron in biological tissue by HPLC. Anal. Biochem. 180:126-130.

29. Kontoghiorges, G. J., S. Chambers, and V. A. Hoffbrand. 1987. Comparative study of iron mobilization from heamosiderin, ferritin and iron(III) precipitates by chelators. Biochem. J. 241:87-92.

30. Slater, T. F., and M. N. Eakins. 1975. Interactions of (+)-cyanidanol-3 with free radical generating systems. In New Trends in the Therapy of Liver Diseases. A. Bertelli, editor, S. Karger AG, Basel, Switzerland. 84-98.

31. Mulligan, M., B. Althaus, and M. C. Linder. 1986. Non-ferritin, nonheme iron pools in rat tissues. Int. J. Biochem. 18:791-798.

32. Linder, M. C., M. Mulligan, and D. Henley. 1983. Low molecular weight iron pools in tissues of the rat and pig. In Structure and Functions of Iron Storage and Transport Proteins. I. Urushusaki editor. Elsevier/Holland, Amsterdam. 465-468.

33. Bolann, B. J., and R. J. Ulvik. 1990. On the limited ability of superoxide to release iron from ferritin. Eur. J. Biochem. 193:899-904.

34. Jacobus, W. E., G. J. Taylor, D. P. Hollis, and R. L. Nunnally. 1977. Phosphorous NMR of perfused working rat hearts. Nature (Lond.). 265:756758.

35. Vander Elst, L., J.-F. Goudemant, J. Mouton, P. Chatelain, Y. M. van Haverbeke, and R. N. Muller. 1990. Amiodarone pretreatment effects on ischemic isovolumic rat hearts: a P-31 NMR study of intracellular pH and high energy phosphate contents evolution. J. Cardiovasc. Pharmacol. 15:377-385. 